\title{
The Nutritional Adequacy of Infant Formula
}

Share this: f

George Kent, Ph.D.

Government agencies that regulate infant formula have been concerned about its safety, worrying about things like contamination with bacteria and insect parts. Questionable formula has been subject to government-ordered recalls. This attention reinforces people's confidence that national governments are ensuring the quality of infant formula. However, national regulatory agencies generally just assume that various versions of infant formula and other foods are safe for children (Kent, 2011).

While many others have commented on safety issues relating to infant formula, few have paid attention to another important point. Safety is about ensuring that the product does not cause direct harm-but that is not enough. There are things infant formula is supposed to do. The quality of infant formula depends not only on its safety, but also on its nutritional adequacy.

Keywords: Infant formula, safety, nutritional adequacy, Codex Alimentarius Clinical Lactation, 2012, Vol. 3-1, 21-25

\section{The Regulatory Context}

At the global level, the primary agency concerned with food quality is the Codex Alimentarius Commission, created by the Food and Agriculture Organization, and the World Health Organization in 1963. It issues nonbinding guidelines regarding food composition and safety. In 1976, at its $11^{\text {th }}$ session, the Codex Alimentarius Commission issued a Statement on Infant Feeding. It said:

...it is necessary to encourage breastfeeding by all possible means in order to prevent that the decline in breastfeeding, which seems to be actually occurring, does not lead to artificial methods of infant feeding, which could be inadequate or could have an adverse effect on the health of the infant (Codex Alimentarius Commission, 1976).

At this session the Commission also adopted a Codex Standard for Infant Formula. The standard, designated as CODEX STAN 72-1981, includes a list of required ingredients and various required quality-control measures. In 1983, the 15th Session adopted amendments to the sections on Food Additives and Labeling. A further amendment to the Labeling section was adopted in 1985 by the 16th Session. Amendments to the vitamin D and B12 amounts were adopted by the 17th (1986) and 22nd (1997) sessions respectively (Codex Alimentarius, 2007).

This core statement of the required ingredients for infant formula is generally accepted throughout the world. The permitted nutrient ranges allow a variety of quite different formulas. The requirements are widely regarded as a minimum standard. Some countries have adopted more stringent requirements.

The primary source of binding regulations regarding foods is national governments. In the United States, the responsibility for regulating children's foods, such as infant formula, is the Food and Drug Administration (FDA), located in the U.S. Department of Agriculture (USDA).

The Federal Food, Drug, and Cosmetic Act defines infant formula in Title 21, Section 321(z) of the United States Code. It is:

...... food that purports to be or is represented for special dietary use solely as a food for infants by reason of its simulation of human milk or its suitability as a complete or partial substitute for human milk (21 U.S. Code 321 (z)).

Section 350a of the act provides specifications regarding adulteration, quality-factor requirements, manufacturing regulations, product testing, and record keeping. It sets out a list of required nutrients and their minimum and maximum quantities. The list includes protein, fat, essential fatty acids (only linoleate is in the list), fifteen different vitamins, and eleven different minerals. The 
list conforms to the recommendations of the Codex Alimentarius Commission.

The U.S. Code of Federal Regulations Title 21, Part 106 specifies infant formula quality-control procedures. Last revised in 2009, it is mainly about quality control during the manufacturing process, and not directly about the quality of the product that emerges from that process (U.S. Code of Federal Regulations (21CFR106) 2009). Part 107, last revised in 2003, states the nutrient requirements and other rules regarding labeling, recalls, etc. (U.S. Code of Federal Regulations (21CFR107) 2003).

U.S. rules have been summarized as follows:

Infant formula, like no other food, is regulated by its own law, the Infant Formula Act of 1980 as amended in 1986. The act sets lower limits on 29 nutrients (so-called "table nutrients" because they appear in table form. U.S. Code of Federal Regulations 21 CFR 107.100). . . . Manufacturers are required to follow "good manufacturing practice," but no requirement for sterility is specified. . . . Powdered formula is not guaranteed nor required to be free of pathogenic organisms (Baker, 2002).

\section{Nutritional Adequacy}

Infant formula is not officially a pharmaceutical product, though in many cases the manufacturers are pharmaceutical companies. If infant formula were to be categorized as a pharmaceutical, under U.S. law it would have to be assessed for both its safety and its effectiveness. Safety is about ensuring the product does no harm in the short term, while effectiveness is about ensuring that it does what it is supposed to do: its functionality. In dealing with pharmaceuticals, for example, if a claim is made that a product will reduce fever, it should be demonstrated scientifically that it does in fact accomplish that. For infant formula, effectiveness can be understood as equivalent to nutritional adequacy. Does infant formula do what it is supposed to do with regard to infants' nutrition?

The only thing the FDA does to ensure nutritional adequacy is to require that all varieties of infant formula conform to the list of required ingredients that was worked out in the 1980s, with a few modifications since then. The FDA usually takes the manufacturers' word on whether they have, in fact, met those requirements.
The underlying assumption is that any infant formula that includes the specified ingredients in the required amounts is both safe and nutritionally adequate. This is a simplistic, reductionist approach, treating something very complex as if it were the same as the sum of its components. It is a bit like suggesting there is no difference between a nice meal based on a variety of fresh and natural ingredients, and what would be obtained by putting a few roughly comparable ingredients into a mixer. To suggest that one can approximate breast milk by putting a few ingredients into a mixer is to grossly underestimate it.

If any infant formula that conforms to the list of required ingredients is nutritionally adequate, how would we explain why so many different infant formula products are available on the market?

In the United Kingdom, for example, one can obtain:

- Infant milks suitable from birth (cows'-milk based),

- Infant milks marketed for hungrier babies, suitable from birth (cows'-milk based),

- Thickened infant milks suitable from birth,

- Soy-protein-based infant milks suitable from birth,

- Lactose-free infant milks suitable from birth, and

- Partially hydrolysed infant milks suitable from birth.

\section{For older infants one can obtain:}

- Follow-on formula suitable from six months of age,

- Partially hydrolysed follow-on formula suitable from six months of age,

- Goodnight milks and food drinks,

- Goodnight milks,

- Food drink, and

- Growing-up milks and toddler milks (Crawley, 2011).

Many new varieties are offered all the time, including versions with a bewildering variety of additives. There are reasons to suspect that the many variations increase profitability for the manufacturers, but offer few significant benefits in terms of children's health (Kent, 2011).

This reductionist approach has dangerous consequences. As nutritionist Carlos Monteiro explains:

Nutrition science is taught and practiced as a biochemical discipline. Practically all nutritionists 
now categorise food in terms of its chemical composition, as do most lay writers. This almost universal perception of nutrition is evident in textbooks and scientific journals, and on food labels, journalism, and "diet books." The identification of food with its chemistry is a defining characteristic of modern nutrition science, as invented in the early 19th century. Seeing food in terms of its chemistry has enabled the industrialization of food systems. In particular, it has made possible the formulation of ultra-processed products from "refined" or "purified" chemical constituents of foods-oils, proteins, carbohydrates, and their fractions-together with "micronutrients"-vitamins and minerals (Monteiro, 2011).

He summarizes: "Identification of food mainly with its chemical constituents at best has limited value, and in general has proved to be unhelpful, misleading, and harmful to public health."

The Codex Statement on Infant Formula of 1976 said, "Numerous formulae have been produced which offer a nutritionally adequate food for infants ..." (Codex Alimentarius, 1976). That depends on how one understands "nutritionally adequate." Elsewhere the Codex Alimentarius Commission said:

The nutritional adequacy of a product can be defined in terms of protein quality and quantity, and content of minerals and vitamins.

Such a product should be considered nutritionally equivalent if:

i. its protein quality is not less than that of the original product or is equivalent to that of casein, and

ii. it contains the equivalent quantity of protein $(\mathrm{N}=6.25)$ and those vitamins and minerals which are present in significant amounts in the original animal products (Codex Alimentarius Commission, 1989).

This is difficult to understand. A food's nutritional adequacy should be assessed in terms of its results, not its ingredients. Infant formula should be viewed as nutritionally adequate only if it is proven to be as good for children as breastfeeding. Any other definition shortchanges children.
The overall quality of infant-formula products should be assessed on the basis of their safety and their nutritional adequacy. Assessing infant formulas only on the basis of their safety and their composition (as in Crawley, 2011) is a serious error. Studying the composition of infant formula is of little help in assessing the risks involved in its use.

There is value to checking the composition of infant formula because it can deteriorate over time, it may be manufactured improperly, and it may be contaminated in various ways. However, that is not the same as checking for nutritional adequacy. Even perfect adherence to imperfect recipes for infant formula puts infants at risk.

The main function of infant food and the associated feeding process is to ensure long-term health-including not only body-building, but also protection against infections and allergies, and facilitating cognitive as well as physical development. The only way to ensure that feeding with any breast-milk substitute is equivalent to breastfeeding would be to compare the health of children who are breastfed with the health of those who use the substitute, not only in the short term, but also in the long term.

In 1981, the Codex Alimentarius Commission said:

Infant formula means a breast-milk substitute specially manufactured to satisfy, by itself, the nutritional requirements of infants during the first months of life up to the introduction of appropriate complementary feeding (Codex Alimentarius Commission 2007, Section 2.1.1).

If we assess formula by its results, rather than by whether its ingredients matched a specific list, we would have to conclude that there has never been an infant formula that would "satisfy, by itself, the nutritional requirements of infants during the first months of life."

Contrary to Codex's 1976 claim that, "Numerous formulae have been produced which offer a nutritionally adequate food for infants" (Codex Alimentarius, 1976), there has never been any infant formula that is nutritionally adequate.

The European Union said, "Infant formula is the only processed foodstuff which wholly satisfies the nutritional requirements of infants during the first months of life until the introduction of appropriate complementary feeding" (EUR-Lex 2011, para 4; also see Article 2(c) 
and Article 3). The statement should be rejected. If infant formula wholly satisfied infants' requirements, there would not be a regular pattern of worse health outcomes for infants who use it.

The industry's lobbying group based in the U.S., the Infant Formula Council, says, "Iron-fortified infant formula is the only safe and effective alternative to breast milk, providing complete nutrition to meet the unique needs of growing infants" (Infant Formula Council 2011). One possible interpretation of "complete nutrition" is that the formulas comply with the list of required ingredients under the law. If they are complete, why do the manufacturers offer additives beyond those required by the law? If nutritionally adequate infant formula had already been developed by the 1980s, why has there been a steady stream of modifications since then?

Perhaps the Infant Formula Council means to say that the formulas are complete in the sense that they meet all infants' nutritional needs. If that is their position, then how would they explain the consistently worse health outcomes with formula feeding when compared with breastfeeding? Either way, the claim that infant formulas are "nutritionally complete" is misleading.

The Infant Nutrition Council based in Australia makes a claim similar to the one by the Infant Formula Council in the U.S.: "Infant formula has been specifically developed to contain all the necessary ingredients needed to meet an infant's nutritional requirements" (Infant Nutrition Council, 2011). If formula has all the ingredients needed to meet nutritional requirements, why add things? And how would they explain the fact that formula feeding leads to worse health outcomes than breastfeeding?

\section{Nutritional Adequacy Should Be Judged By Results}

While nutritional adequacy in the sense of functionality (results) is not covered explicitly in current standards for infant formula, it has been considered. In the discussion leading up to the adoption of the rules relating to infant formula in the U.S. (21 CFR Parts 106 and 107), rules were proposed that would have required that "formula will support optimal infant growth and health" (U.S. Federal Register, 1996).

The proposal said, "the FDA has tentatively concluded, therefore that an evaluation of the ability of a formula to support healthy growth must be made under its most demanding conditions of use, i.e., when it is used as the sole source of nutrition." It also said, "the determination of physical growth rate is the most valuable component of the clinical evaluation of infant formulas." However, this recognition of the importance of physical growth did not carry over into the rules that were finally adopted.

Although there are issues regarding the precise relationship between infant growth and health (Burger \& Newman, 2011; De Onis et al., 2004; Fomon, 2004; Garza \& de Onis, 1999), there is clear consensus that healthy infants grow rapidly (but not too rapidly), and have low rates of morbidity and mortality. International agencies have worked out clear standards for normal growth rates of infants and young children.

When the World Health Organization investigated the adequacy of exclusive breastfeeding during the first six months of infants' lives, their study focused not on the composition of the diet, but on its results.

In evaluating the nutrient adequacy of exclusive breastfeeding, infant nutrient requirements are assessed in terms of relevant functional outcomes. Nutrient adequacy is most commonly evaluated in terms of growth, but other functional outcomes, e.g. immune response and neurodevelopment, are also considered to the extent that available data permit...

In determining the optimal duration of exclusive breastfeeding in specific contexts, it is important that functional outcomes, e.g., infant morbidity and mortality, also are taken into consideration (Butte et al., 2002, p. vii).

Various feeding methods could be studied by examining their impacts on these outcome indicators. The common standards would make it possible to compare the nutritional adequacy of different methods of feeding.

Though people may believe that agencies, such as the Codex Alimentarius Commission, and the FDA actively work to ensure the nutritional adequacy of infant formula, they do not. In fact, the FDA explicitly states that it does not approve functional claims for foods (U.S. Department of Health and Human Services, 2011). It does not address claims that particular infant formulas help infants to grow or to have good eyesight. There is no agency that ensures the functional quality of infant formula. 
So long as feeding with infant formula consistently produces worse health outcomes, formula should not be viewed as nutritionally adequate. Feeding with formula might be claimed to be adequate in the sense that it can keep a child alive. But it should never be implied to be as good, or nearly as good, as breastfeeding.

\section{References}

Baker, R.D. (2002). Commentary: Infant formula safety. Pediatrics. 110(4), 833-835. http://pediatrics.aappublications.org/cgi/content/full/110/4/833

Burger, S.E., \& Newman, S.D. (2011). Can lactation consultants find appropriate uses for the World Health Organization Growth Curves?" Clinical Lactation, 2(2), 14-19.

Butte, N. F., Lopez-Alarcon, M.G., \& Garza, C. (2002). Nutrient adequacy of exclusive breastfeeding for the term infant during the first six months of life. Geneva, Switzerland: World Health Organization. Retrieved from: http://www.who.int/entity/nutrition/publications/infantfeeding/9241562110/en/

Codex Alimentarius Commission. (1976). Statement on infant feeding, CAC/MISC-2-1976. Retrieved from: http://www.codexalimentarius.net/download/standards/301/CXA_002e.pdf

Codex Alimentarius Commission. (1989). Codex general guidelines for the utilization of vegetable protein products (VPP) in foods. CAC/ GL 4-1989. Retrieved from: http://www.codexalimentarius.net/ download/standards/326/CXG_004e.pdf

Codex Alimentarius Commission. (2007). Standards for infant formula and formulas for special medical purposes intended for infants. CODEX STAN 72-108. [Formerly CAC/RS 72-1972. Adopted as a world-wide Standard 1981.Amended 1983, 1985,1987. Revision 2007] Retrieved from: http://www.codexalimentarius.net/ download/standards/288/CXS_072e.pdf

Crawley, H., \& Westland, S. (2011). Infant milks in the UK. Abbots Langley, United Kingdom: Caroline Walker Trust. Retrieved from: http://www.cwt.org.uk/pdfs/infantsmilk_web.pdf

De Onis, M., Garza, C., Victora, C.G., Bhan, M. K., \& Norum, K.R. (2004). The WHO Multicentre Growth Reference Study (MGRS): Rationale, planning, and implementation. Food and Nutrition Bulletin, 25(1). Retrieved from: http://www.inffoundation.org/FNB/FNBindexNEW.html
EUR-Lex. (2011). Commission directive 2006/141/EC of 22 December 2006 on infant formulae and follow-on formulae and amending Directive 1999/21/EC (1). Official Journal of the European Union. EUR-Lex: Access to European Union Law. Retrieved from: http://eur-lex.europa.eu/JOHtml.do?uri=OJ:L:2006:401: SOM:EN:HTML

Fomon, S.J. (2004). Assessment of growth of formula-fed infants: Evolutionary considerations. Pediatrics, 113(2), 389-393.

Retrieved from: http://pediatrics.aappublications.org/cgi/content/full/113/2/389

Garza, C., \& de Onis, M. (1999). A new international growth reference for young children. American Journal of Clinical Nutrition, 70(1), 169S-172S. Retrieved from: http://www.ajcn.org/cgi/ content $/$ full $/ 70 / 1 / 169 S$ ? maxtoshow $=\&$ HITS $=10 \&$ hits $=10 \& R$ ESULTFORMA

Infant Formula Council. (2011). What nutrients are present in infant formula and why are they included? IFC. Retrieved from: http:// www.infantformula.org/fags

Infant Nutrition Council. (2011). Infant formula information. INC. Retrieved from: http://infantnutritioncouncil.com/formulainformation/

Kent, G. (2011). Regulating infant formula. Amarillo, Texas: Hale Publishing.

Monteiro, C. (2011). The big issue is ultra-processing. "Carbs": The answer. World Nutrition, 2(2), 86-97. Retrieved from: http:// wphna.org/2011_feb_wn4_cam5.htm

U.S. Code of Federal Regulations. Title 21 Part 107 (21CFR107). (2003). Retrieved from: http://www.access.gpo.gov/nara/ cfr/waisidx_03/21cfr107_03.html

U.S. Department of Health and Human Services. (2011). Is it really FDA approved? Washington, D.C.: USDHHS. Food and Drug Administration. Retrieved from: http://www.fda.gov/ForConsumers/ConsumerUpdates/ucm047470.htm

U.S. Federal Register. (1996). Proposed rules for 21 CFR Parts 106 and 107 ... for the production of infant formula 61:132 (July 9). U.S. Federal Register. Retrieved from: http://www.fda.gov/Food/FoodSafety/Product-SpecificInformation/InfantFormula/GuidanceRegulatoryInformation/RegulationsFederalRegisterDocuments/ $\underline{\mathrm{ucm} 106557 . \mathrm{htm}}$

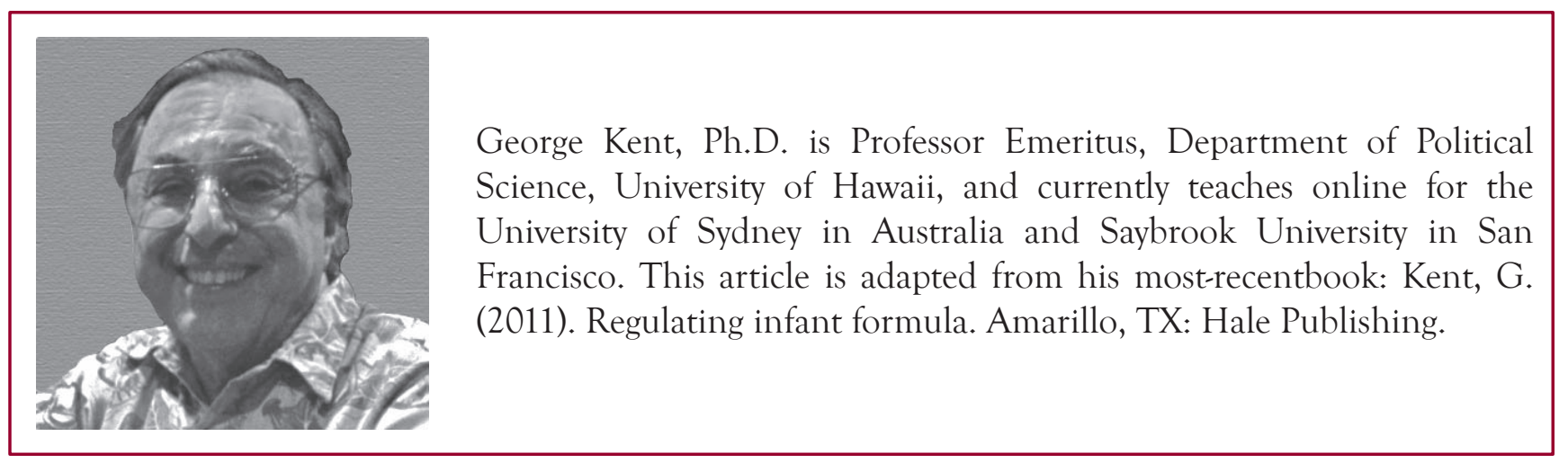

